\title{
Reversible neuropsychological deficits after mild traumatic brain injury
}

\author{
M Keller, B Hiltbrunner, C Dill, J Kesselring
}

\begin{abstract}
Objectives-To determine the influence of motivation on performance in a divided attention test of patients after mild traumatic brain injury (MBI).

Methods-Comparison of the performance of 12 patients with MBI with 10 patients with severe brain injury (SBI) and 11 healthy controls in a computer supported divided attention task before (T1) and after (T2) verbal motivation. Results-At T1, the MBI group performed the same as the SBI group but significantly worse than the controls in all variables. At T2, the MBI group performed worse than the controls at $\mathrm{T} 2$ but the results were equal to the results of the controls at $\mathrm{T} 1$ and significantly better than the SBI group at $\mathrm{T} 1$ or $\mathrm{T} 2$. At $\mathrm{T} 2$ the $\mathrm{MBI}$ group performed at the level of published norms for the rest.

Conclusion-Before verbal motivation the MBI group's results in the divided attention task were comparable with those from patients with severe brain injury. They failed to exploit their performance potential when it depended on self motivation but were able to perform at the level of the control group when external motivation was applied.
\end{abstract}

(F Neurol Neurosurg Psychiatry 2000;68:761-764)

Keywords: brain injury; attention; neuropsychology

Mild traumatic brain injury ${ }^{1}(\mathrm{MBI})$ represents about $80 \%$ of the sequelae of civilian traumatic brain injury in Switzerland. It is estimated that about 6000 new cases occur every year. About $70 \%$ occur during leisure activities, mostly sports and driving, and about 30\% happen at work. ${ }^{2}$ Many patients who sustain MBI complain of numerous symptoms including headache, dizziness, fatigue, irritability, difficulty in concentrating and performing mental tasks, impairment of memory, insomnia, depressed mood, ${ }^{3}$ and reduced tolerance to stress, emotional excitement, or alcohol. About 4\% are associated with a whiplash injury. ${ }^{4}$ In these patients dysaesthesia and aching pain in the neck and in the upper limbs may be prominent, and the muscles may be tense and tender to palpation. ${ }^{5}$ Most patients with MBI return to work and resume a productive life within a few weeks (median time off work 9 days) albeit $10 \%$ to $20 \%$ remain symptomatic after 1 year. $^{4}$ Between $0.06 \%$ and $2.5 \%$ (three of 4899 isolated cases of concussion; 69 of 2731 patients with a whiplash injury in addition to concussion $^{3}$ ) remain permanently profession- ally disabled and with significant loss of quality of life. ${ }^{2}$ Their cognitive and affective symptoms may far exceed what might be expected from the initial clinical indicators of damage to the CNS. Some investigators claim that minute contusions or diffuse axonal injury are the likely cause. ${ }^{67}$ Psychological therapies may enhance the long term functional outcome, ${ }^{8}$ but psychological intervention would be unlikely to reverse neuropsychological deficits that are directly due to specific brain lesions. In the present study, the performance of patients up to 70 months after an MBI was compared with that of a group of patients with vascular or traumatic brain lesions and healthy controls on a computerised test of attention and concentration before and after a motivating intervention.

\section{Method}

Three groups of subjects were recruited. Two groups wer made up from 22 patients from the inpatient rehabilitation programme at the Neurorehabilitation Unit of Valens, Switzerland. Twelve patients (mild brain injury group, $\mathrm{MBI}$ ), had sustained a mild traumatic brain injury 10 to 70 months before testing. Their mean age was 40.3 years. Mild traumatic brain injury was diagnosed in patients with an admission Glasgow coma score of 13 to 15 , no or only brief loss of consciousness (up to a few minutes), a post-traumatic amnesia of less than a few hours, no or transient focal neurological signs, and no signs of traumatic brain damage on CT or MRI examination. The neurological examination performed by a staff neurologist was normal. Eleven of 12 subjects had also sustained a whiplash injury grade I or II according to the classification of the Quebec Task Force. ${ }^{9}$ The second group consisted of 10 patients with moderate to severe brain damage (SBI), one after a severe head injury with frontotemporal contusions, four with an ischaemic cerebrovascular infarct, and five with brain haemorrhage 1.5 to 17 months before testing. Their mean age was 53.6 years. Their neurological examination and CT/MRI of the brain were abnormal. Eleven healthy subjects (controls) lacking any history of neurological disease or traumatic brain injury served as control group. Their mean age was 37 years. Men were overrepresented in the SBI group compared with the two other groups $(\mathrm{p}<0.05)$. The three groups had similar proportions with unskilled and skilled employment and with a university degree. Table 1 shows the demographic characteristics. Subjects with a progressive CNS disorder, a history of psychiatric illness, and drug or alcohol misuse or who were not fluent in German were excluded. All 
Table 1 Demographic characteristics of mild brain injury and severe brain injury patients and healthy controls

\begin{tabular}{|c|c|c|c|}
\hline & $\begin{array}{l}\text { Mild brain injury } \\
(n=12)\end{array}$ & $\begin{array}{l}\text { Severe brain injury } \\
(n=10)\end{array}$ & $\begin{array}{l}\text { Controls } \\
(n=11)\end{array}$ \\
\hline Male & 7 & $8^{\star}$ & $5^{\star}$ \\
\hline Age (mean $(95 \% \mathrm{CI})$ ) & $40.3(33.347 .1)$ & $53.6(41.4-65.9)$ & $37(29.9-44.1)$ \\
\hline \multicolumn{4}{|l|}{ Education: } \\
\hline Unskilled & 5 & 2 & 1 \\
\hline Skilled labour & 5 & 7 & 8 \\
\hline University degree & 1 & 1 & 2 \\
\hline $\begin{array}{l}\text { Months from accident to test:mean } \\
\text { (range) }\end{array}$ & $38 \quad(10-70)$ & $5.5(1-17)$ & \\
\hline
\end{tabular}

patients had been admitted to a 6 week intensive rehabilitation programme to foster independence and professional reintegration. All lived independently and drove a car. No participant was in psychiatric care before admission. Two of 12 patients of the MBI group worked full time, three part time, and seven were unemployed. No patient of the SBI group worked. An extensive neuropsychological evaluation was performed on all study patients by $\mathrm{MK}$, a neuropsychologist and specialist in driving aptitude (traffic psychologist), or by $\mathrm{CD}$, a neuropsychologist, as part of the case documentation. The study procedures were performed immediately thereafter. The control subjects were recruited among the staff of the clinic not involved in patient care and unaware of the study hypothesis. All patients and controls were otherwise healthy at the time of their examination. There were no unsettled liability claims. Participants in the study were asked to provide oral informed consent according to Swiss laws. No monetary compensation was offered.

TEST

Vigilance and attention are supported by distributed neural networks involving the brain stem and both hemispheres ${ }^{10} 11$ They are prone to dysfunction after traumatic brain injuries or extensive ischaemic cerebral damage. Measures of vigilance and attention are sensitive markers of brain dysfunction. ${ }^{12-15}$ The Wiener $\mathrm{D}$ test, ${ }^{16}$ a computer supported divided attention test, was chosen from several simple and complex attention tests for this study because it is easy to perform, short, well accepted by patients, and used broadly in Germany, Switzerland, and Austria. The test requires subjects to respond to each of 180 auditory or visual stimuli of 1.58 (form $\mathrm{A}$ ) or 0.95 seconds (form B) duration by pressing a modality specific button. The computer provides the number of on time responses, delayed responses, and incorrect responses and of omitted responses as dependent variables. Certain responses are counted twice, for example, a delayed but correct response, thus limiting the possibilities of error analysis. Brenner et al published sex, age, and education stratified ref-

Table 2 Results (means (95\% CI)) of form A of the Wiener D test at baseline (T1)

\begin{tabular}{lccc}
\hline Response & Mild brain injury $(n=12)$ & Severe brain injury $(n=10)$ & Controls $(n=11)$ \\
\hline On time & $132.7(117.9-147.5)$ & $113.7(85.3-142.1)$ & $171.0(165.4-176.6)$ \\
Delayed & $20.2(12.4-27.0)$ & $23.7(15.1-32.3)$ & $4.7(1.4-8.1)$ \\
Wrong & $17.4(7.8-27.1)$ & $22.7(4.4-41.0)$ & $4.1(1.1-9.1)$ \\
Omitted & $19.5(12.2-26.8)$ & $30.7(11.3-50.1)$ & $1.8(0.3-3.3)$ \\
\hline
\end{tabular}

erence values (means, SD, number of correct, false, delayed, and omitted responses as well as reaction times for each subtest), for healthy controls $(n=300)$, for patients with brain damage $(n=329)$, and for psychiatric patients $(n=171) .^{17}$

\section{PROCEDURES}

On admission to the clinic, the patients' medical records were reviewed and a physical and neurological evaluation was performed. $\mathrm{Pa}-$ tients were recruited for the study if they were able to perform the study procedures and fulfilled inclusion and exclusion entry criteria. All subjects were tested within 5 working days of the initial assessment. The study procedures followed the diagnostic neuropsychological assessment. They were told that the goal of the research project was to investigate their capacity to concentrate and informed about the test to be performed. However, they were not told that the test had to be done twice. After completing the test for the first time, the subjects were told that the results were important for determination of safe driving, whatever their actual performance had been. They were encouraged to repeat the test to verify the results after the following identical comment to each one: "This test is important for safe driving of your car. Could you do better?". All subjects repeated the test within 12 hours, most within 1 hour of the initial test. All subjectsthat is, patients and healthy controls received the same concise instructions. At the end of the test the subjects were reassured that they had not been submitted to a fitness for driving test which would have implied a more thorough investigation of cognitive and psychomotor abilities and often includes a formal driving test. The procedures and instructions were reviewed by an internal, multidisciplinary review board before the start of the study.

\section{ANALYSIS}

The significance level $(\alpha)$ was set at $5 \%$. Differences between the groups in age and sex were evaluated with Student's $t$ test. The means of the individual dependent variables of form $\mathrm{A}$ and $\mathrm{B}$ at times $\mathrm{T} 1$ (baseline test) and T2 (repeat test) of the three groups (MBI, SBI, controls) were compared with the $F$ test. Ninety five per cent upper and lower confidence intervals (95\% CIs) of the values were calculated. $\mathrm{K} \times \mathrm{c}$ contingency tables of ordinal variables (number of on time, delayed, false, and omitted responses) were calculated. They confirmed the results obtained with the $F$ test.

\section{Results}

The results of the Wiener D test are summarised in tables 2-5. All members of the three groups were able to carry out form A of the test. Six of 10 patients of the SBI group were unable to complete form B. Results of form A of the Wiener D test are shown in tables 2 and 3): At baseline (T1) the controls provided statistically significant better results than the two other groups except for the number of wrong responses; this did not differ statistically between the MBI and control group (table 2). 
Table 3 Results (means (95\% CI)) of form A of the Wiener D test after a motivating intervention (T2)

\begin{tabular}{lccc}
\hline Response & Mild brain injury $(n=12)$ & Severe brain injury $(n=10)$ & Controls $(n=11)$ \\
\hline On time & $167.3(159.8$ to 174.9$)$ & $111.3(77.5$ to 145.1$)$ & $177.9(175.9$ to 180.0$)$ \\
Delayed & $5.8(2.3$ to 9.3$)$ & $21.5(10.8$ to 32.2$)$ & $0.7(-0.2$ to 1.7$)$ \\
Wrong & $7.2(2.8$ to 11.5$)$ & $24.2(11.8$ to 36.6$)$ & $2.0(0.0$ to 4.0$)$ \\
Omitted & $2.6(0.4$ to 4.8$)$ & $35.2(14.1$ to 56.3$)$ & $0.4(-0.1$ to 0.8$)$ \\
\hline
\end{tabular}

Table 4 Results (means (95\% CI)) of form B of the Wiener D test at baseline (T1)

\begin{tabular}{llcc}
\hline Response & Mild brain injury $(n=12)$ & Severe brain injury $(n=10)$ & Controls $(n=11)$ \\
\hline On time & $33.6(23.1-44.2)$ & $9.8(2.0-17.6)$ & $118.0(89.3-146.7)$ \\
Delayed & $70.3(56.5-84.1)$ & $61.8(30.9-92.8)$ & $46.0(21.4-70.6)$ \\
Wrong & $18.7(8.7-28.8)$ & $34.0(15.4-52.6)$ & $9.7(4.7-14.8)$ \\
Omitted & $68.5(52.0-85.1)$ & $80.3(50.3-110.3)$ & $12.4(6.1-12.4)$ \\
\hline
\end{tabular}

Table 5 Results (means (95\% CI)) of form B of the Wiener D test after a motivating intervention (T2)

\begin{tabular}{llcc}
\hline Response & Mild brain injury $(n=12)$ & Severe brain injury $\left(n=4^{\star}\right)$ & Controls $(n=11)$ \\
\hline On time & $92.8(66.3$ to 119.2$)$ & $7.0(-1.7$ to 15.7$)$ & $146.2(124.6$ to 167.8$)$ \\
Delayed & $57.9(44.4$ to 71.4$)$ & $65.7(-33.9$ to 165.2$)$ & $27.1(6.3$ to 47.9$)$ \\
Wrong & $13.8(8.0$ to 19.6$)$ & $30.7(-35.4$ to 96.7$)$ & $4.3(1.9$ to 6.7$)$ \\
Omitted & $24.3(10.8$ to 37.8$)$ & $81.7(-19.2$ to 182.5$)$ & $4.8(1.9$ to 7.7$)$ \\
\hline
\end{tabular}

$\star 6 / 10$ Patients were unable to complete the test.

The values of the control group were within the limits of published norms; those of the two other groups were outside these limits. ${ }^{17}$ After the motivating intervention (T2) the MBI and control group differed significantly in terms of on time $(t=-2.53, \mathrm{p}=0.03)$ and delayed $(t=2.76, \quad \mathrm{p}=0.02)$ responses, the controls achieving better results (table 3 ). The SBI group performed worse than the two other groups in all four categories of responses. The SBI and control group achieved no significant change in their performance from $\mathrm{T} 1$ to $\mathrm{T} 2$ (table 2 and 3) whereas the MBI group showed a significant improvement in three of the four categories of responses (on time, delayed, and omitted responses). The results of form B of the Wiener D test are shown in table 4 and 5: The MBI group performed significantly worse than the controls at baseline in terms of on time and omitted responses (table 4). At T2 statistically significantly differences from controls were found in on time $(t=3.07, \mathrm{p}=0.02)$, delayed $(t=2.3, \mathrm{p}=0.05)$, wrong $(t=3.19$, $\mathrm{p}=0.02)$, and omitted $(t=3.13, \mathrm{p}=0.01)$ responses (table 5). However, all results were within published norms of age and socioeconomic level matched controls. ${ }^{17}$ None of the T2 results of the MBI group were statistically different from the $\mathrm{T} 1$ results of the controls and they were within published limits of age and socioeconomic level matched controls. ${ }^{17}$ At $\mathrm{T} 1$, one of 12 and none of 12 subjects achieved mean published reference values of on time responses in forms $\mathrm{A}$ and $\mathrm{B}$ of the Wiener $\mathrm{D}$ test, respectively, compared with nine of 12 and six of 12 subjects respectively at T2.

\section{Discussion}

The causes of disabling cognitive deficits many months after a mild traumatic brain injury continue to be debated. ${ }^{18-21}$ The accident history and findings on initial neurological examination often do not predict significant lasting cognitive deficits. ${ }^{20}$ Brain imaging and functional brain studies seldom demonstrate structural brain damage ${ }^{20}$ and abnormal neuropsychological tests do not prove brain damage. ${ }^{22}$ Other causes need to be considered to explain the cognitive symptoms of many such patients. The patients with MBI in this study exhibited attention and concentration deficits during the initial testing comparable with those of the SBI group.

As no expected level of performance was set before the first test, the results of the MBI group do not reflect an examination failure on account of learnt helplessness ${ }^{23}$ which responded to encouragement before the second testing. The low level of performance on initial testing may rather reflect an insufficient motivation and lack of confidence. Radanov et $a l^{4}$ pointed out that patients with chronic neck pain after a whiplash injury tend to judge their performance on neuropsychological tests lower than what they actually achieve.

When the patients with MBI were told that the test was important for safe driving of their car, they readily agreed to repeat the test and achieved results which were not statistically different from those of the control group during the first test. The results lay within the performance range of an age and education matched reference group. ${ }^{17}$ The improvements were obtained even though the tests were performed at the end of the diagnostic neuropsychological investigation of 3 to 3.5 hours duration which might lead to a prediction of a decline in performance during repeat testing.

The comment about driving did not significantly improve the retesting results of the SBI group. The subjects already attempted to deliver the best possible result during the initial testing. At T2 the results of four of the 10 patients deteriorated, the others (six of 10) terminated the test prematurely due to a catastrophic reaction. ${ }^{25} 26$

No subject was threatened with revocation of the driver's licence. No information was given on the expected performance, no instructions on how to improve the results and no rehearsals were allowed before the repeat testing. It is unlikely that experience with the test accounts for the improved results of the patients with MBI as only a moderate improvement was seen in controls and none in the patients with SBI.

Most subjects repeated the test within 1 hour of the first test. It would have been interesting to repeat the motivating procedure a third time to investigate if the MBI group would have achieved further performance gains. However, it would have been difficult to request a third performance without altering the study conditions or misleading the subjects. In any case, most patients with MBI achieved normal performance with a $19 \%$ (form A) and $176 \%$ (form B) increase in on time scores from baseline.

Only a tentative explanation may be offered for the striking improvement of the performance of patients with MBI. The MBI group may have taken the comment after the initial testing as a threat to their independence and mobility. Hence the possibility of an additional loss of quality of life may have allowed them to mobilise latent mental resources. ${ }^{27}$ It is also 
possible that months and in many cases years of self perceived disability generates expectation of failure and poor motivation to perform even when capacity to perform is retained. Concern about loss of driving may have induced the motivation to produce full effort.

Although the motivating intervention may have improved the performance of both the MBI and the controls at both levels of test difficulty, the net improvement of the controls was less (presumably because they performed closer to their maximum on T1) than that of the MBI and the mean test results of the patients with $\mathrm{MBI}$ at T2 remained lower than those of the controls. This may indicate that insufficient motivation acted in concert with other factors such as chronic cervical musculoskeletal pain, ${ }^{28}$ headache, ${ }^{29}$ sleep disorder, and depressed mood $^{29-31}$ or inadequate coping with the consequences of the accident, ${ }^{15}$ each of which might contribute to poor attention.

Additional studies are needed to specify how motivational factors, premorbid personality, pain, and emotional disorder might affect neuropsychological test performance in patients with MBI. Therapeutic strategies may then be developed to activate the performance potential to faciliate professional reintegration. In some of our patients this approach and the support of the employer for a staggered return to work led to a successful professional reintegration, at least part time, for some patients with MBI despite the longstanding unemployment after their accident.

We are grateful to Dr Ruedi Fischer, Suva Luzern, Switzerland and to Professor Alfred Stähli, NTB, Buchs, Switzerland for their support in statistics, to Dr Michael Alexander, Beth Israe Deaconess Hospital, Boston, USA for reviewing and commenting on the manuscript, and Mrs Marianna Streuli for her secretarial contribution.

1 Kay T, Harrington DE, Adams A, et al. Special Interest Group of the American Congress of Rehabilitation Medicine: definition of mild traumatic brain injury. Fournal of Head Trauma Rehabilitation 1993;8:86-7.

2 World Health Organization The ICD-10 classification of mental and behavioural disorders. Geneva: WHO, 1992.

3 Fischer R, Glückler E. Sumest Medizinische Statistik Suva, Fischer R, Glückler E. Sumest Medizinische S
Tafelband 1991-2. Luzern: Verlag Suva, 1998.

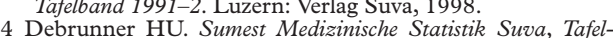
Debrunner HU. Sumest Medizinische Statist

5 Pearce JMS. Polemics of chronic whiplash injury. Neurology 1994;44:1993-7.

6 Oppenheimer DR. Microscopic lesions in the brain following head injury. F Neurol Neurosurg Psychiatry 1968;31:299306.
7 Blumbergs PC, Scott G, Manavis J, et al. Topography of axonal injury as defined by amyloid prcursor protein and the sector scoring method in mild and severe closed head injury. F Neurotrauma 1995;12:565-72.

8 Anderson SW. Cognitive rehabilitation in closed head injury. In: Rizzo M, Tranel D, eds. Head injury and postconcussive syndrome. Edinburgh: Churchill Livingstone, 1996; 23:457-68.

9 Quebec Task Force on Whiplash-Associated Disorders. The Quebec whiplash-associated disorders cohort study. Spine 1995;20(suppl 8):12-20S.

10 Mesulam M-M. Attention, confusional states and neglect. In: Mesulam M-M, eds. Principles of behavioral neurology. Philadelphia: FA Davis, 1985;3:125-68.

11 Mesulam M-M. Large-scale neurocognitive networks and distributed processing for attention, language, and memory. Ann Neurol 1990;28:597-613.

12 Lezak MD. Neuropathology for neuropsychologists. In: Lezak MD, eds. Neuropsychological assessment. 3rd ed. Oxford: Oxford University Press, 1995;7:170-276.

13 Hugenholtz H, Stuss DT, Stethem LL, et al. How long does it take to recover from a mild concussion? Neurosurgery 1988;22:853-8.

14 Batchelor J, Harvey AG, Bryant R. Stroop colour word test as a measure of attentional deficit following mild head injury. Clin Neuropsychol 1995;9:180-6.

15 Cicerone KD. Attention deficits and dual task demands after mild traumatic brain injury. Brain Injury 1996;10:7989

16 Berg M. Benutzerhandbuch zum Determinationsgerät. Version 2.2. Wiener Determinationsgerät. Dr G Schuhfried Ges.mbH, Jan 14, 1992.

17 Brenner H, Klein W, Schirmacher D. Wiener Determinationsgerät - Normen für internistische Rehabilitationskliniken. Zeitschrift für Klinische Psychologie 1981;10:167-76.

18 Binder LM. A review of mild head trauma. Part II: Clinical implications. F Clin Exp Neuropsychol 1997;19:432-57.

19 Gentili M, Nichelli P, Schoenhuber R, et al.Neuropsychological evaluation of mild head injury. $\mathcal{F}$ Neurol Neurosurg Psychiatry 1985;48:137-40.

20 Alexander MP. Mild traumatic brain injury: pathophysiology, natural history and clinical management. Neurology 1995;45:1253-60

21 Stuss DT. Editorial: a sensible approach to mild traumatic brain injury. Neurology 1995;45:1251-2.

22 Goldstein G. Neuropsychological assessment of adults. In: Goldstein G, Nussbaum D, Beers SR, eds. Neuropsychology. New York: Plenum Press, 1998;4:63-81.

23 Seligman MEP. Helplessness. On depression, development and death. San Francisco: NH Freeman, 1975.

24 Radanov BP, Di Stefano G, Schnidrig A, et al. Cognitive functioning after common whiplash. Arch Neurol 1993;50: 87-91.

25 Goldstein K. After-effects of brain-injuries in war. New York: Grune and Stratton, 1942

26 Sturm W, Büssing A. Zum Einfluss motivierender Testinstruktionen auf die Reaktionsleistung hirngeschädigter Patienten. Nervenarzt 1982;53:395-400.

27 Mc Clelland D, Winter D. Motivating economic achievement. New York: Free Press, 1969.

28 Moss-Morris R, Petrie KJ, Large RG, et al. Neuropsychological deficits in chronic fatigue syndrome: artifact or reality? F Nerurol Neurosurg Psychiatry 1996;60:474-7.

29 Keidel M, Yaguez L, Wilhelm H et al. Prospektiver Verlauf neuropsychologischer Defizite nach zervikozephalem Akzelerationstrauma. Nervenarzt 1992;63:731-40.

30 Cassens G, Wolfe L, Zola M. The neuropsychology of depression. 7 Neuropsychiatry Clin Neurosci 1990;2:202-13.

31 Parker RS. The spectrum of emotional distress and personality changes after minor head injury incurred in a motor vehicle accident. Brain Injury 1996;10:287-302. 